\title{
Conservation Genomics Reveals Low Connectivity Among Populations of Threatened Roseate Terns in the Atlantic Basin
}

Paige Byerly ( $\sim$ pabyerly@gmail.com )

Smithsonian Conservation Biology Institute https://orcid.org/0000-0003-0121-1849

R. Terry Chesser

USGS: US Geological Survey

Robert Fleischer

Smithsonian Conservation Biology Institute

Nancy Mclnerney

Smithsonian Conservation Biology Institute

Natalia Przelomska

Royal Botanic Gardens Kew

Paul Leberg

University of Louisiana at Lafayette

\section{Research Article}

Keywords: conservation genomics, genetic structuring, population connectivity, seabird, Sterna dougallii, roseate tern

Posted Date: December 22nd, 2021

DOI: https://doi.org/10.21203/rs.3.rs-1097178/v1

License: (9) This work is licensed under a Creative Commons Attribution 4.0 International License. Read Full License 


\section{Abstract}

While the effects of barriers to dispersal such as population declines, habitat fragmentation, and geographic distance have been well-documented in terrestrial wildlife, factors impeding the dispersal of highly vagile taxa such as seabirds are less well understood. The roseate tern (Sterna dougallii) is a globally distributed seabird species, but populations tend to be both fragmented and small, and the species is declining across most of its range. Within the Atlantic Basin, past work has shown differentiation among roseate terns breeding on different continents, but these results were generated with a limited number of microsatellite markers. Relationships between breeding populations in the Northwestern Atlantic and the Caribbean have never been analyzed. We evaluated population structuring of roseate tern populations in North America and the Azores using both microsatellite markers and singlenucleotide polymorphisms generated through targeted sequencing of Ultra-conserved Elements. For both marker types, we found significant genetic differentiation among all 3 populations and evidence for moderate contemporary unidirectional gene flow from the Caribbean to the Azores, but not among other populations. Within the Caribbean metapopulation, we found high rates of unidirectional migration from the Virgin Islands to Florida, potentially indicative of movement from source population to sink or an artifact of dispersal among other unsampled populations in the Caribbean region. These observations have significance for species persistence in the Atlantic, as our results suggest that loss of genetic diversity within populations is unlikely to be buffered by inflow of new alleles from other breeding populations.

\section{Introduction}

Population connectivity, or migration of breeding individuals between populations, can be crucial for the persistence of species because periodic influxes of new genetic material can help maintain adequate levels of genetic diversity in small and declining wildlife populations (Chesser 1991). Human activities in the Anthropocene have led to habitat fragmentation and widespread declines across wildlife taxa (Dirzo et al. 2014; McCauley et al. 2015), both of which can alter historical connectivity patterns (Hess 1996). When connectivity is altered or severed, populations can become isolated, which can lead to subsequent erosion of genetic diversity (Johnson et al. 2004; Athrey et al. 2011; Tracy \& Jamieson 2011; Leigh et al. 2019). This loss of diversity can compromise both population-wide fitness (Reed \& Frankham 2003) and the adaptive potential of populations in the face of environmental change (Pauls et al. 2013). Effects of isolation are exacerbated as populations decline, with smaller populations at greater risk of deleterious fitness effects via inbreeding depression (Frankham 1996), which can contribute to further population declines (Crnokrak \& Roff 1999; O'Grady et al. 2006). Quantifying connectivity between populations has therefore become increasingly recognized as a priority action for the conservation of threatened and endangered species (Pierson et al. 2016; Funk et al. 2018; Ralls et al. 2018; Hoban et al. 2020).

Although connectivity is sometimes inferred by a species' movement capabilities, empirical quantification of gene flow between populations is necessary both because dispersal is not always determined by movement potential (Lombal et al. 2020) and because gene flow is not always facilitated through 
dispersal (Bensch et al. 1998; Peterson et al. 2014). This disparity between potential and actual movement is exemplified by highly mobile avian taxa such as seabirds. Most seabird species have the potential to disperse across vast distances. Accordingly, they typically exhibit an overall lack of genetic structure among populations within the same oceanic basin (Tigano et al. 2015), with dispersal among populations typically inhibited by geographic barriers such as land, but not by distance between breeding sites (Genovart et al. 2003; Bicknell et al. 2012; Mariano-Jelicich \& Madrid 2014; Wojczulanis-Jakubas et al. 2015; Yannic et al. 2016; Quillfeldt et al. 2017). As many seabirds are migratory, population connectivity is often linked to wintering movements, with dispersal aided by movement along migratory routes (Szczys et al. 2017) or by mixing of geographically disjunct populations on shared wintering grounds, resulting in individuals following conspecifics to new breeding populations (Sonsthagen et al. 2019). However, population structuring has also been detected among seabirds on relatively small spatial scales (Nuss et al. 2016; Sruoga \& Butkauskas 2006). Restricted gene flow between seabird populations may indicate other isolating mechanisms at work, including philopatry (Hailer et al. 2011; Welch et al. 2012), assortative mating due to adaptive differences (Lombal et al. 2017; Nunes 2018), or seascape variables such as marine currents or winds (Nuss et al. 2016). Restricted dispersal can also result from anthropogenic influences such as habitat loss, which can lead to population declines and range contractions that have the potential to alter historical dispersal regimes among populations (Cristofari et al. 2019; Peery et al. 2010).

The roseate tern (Sterna dougallii) is a globally distributed seabird species, but most populations are classified as threatened and the species is declining across its range. In North America, subspecies $S$. $d$. dougallii is separated into federally endangered Northwestern Atlantic (hereafter, Northwestern) and threatened Caribbean metapopulations (USFWS 2010). The Northwestern population is known to have experienced substantial declines in the 20th century. Long-term population dynamics within the Caribbean are not known, but extirpations and range contractions have been observed at multiple locations within the Caribbean, and monitored populations are declining (Zambrano et al. 2000; Soanes et al. 2020). There is thought to be no gene flow between the Northwestern Atlantic and Caribbean metapopulations based primarily on potential morphological differences, geographical separation, and a lack of band return evidence (Shealer \& Saliva 1992; USFWS 2010).

The assumption that roseate tern metapopulations in North America do not interbreed requires validation. Morphological differences among seabirds can be a product of environmental conditions and are not necessarily representative of genetic differentiation (Genovart et al. 2003; Lashko 2004; WojczulanisJaukubas et al. 2015). Despite an extensive long-term research program in the Northwest, roseate tern dispersal within the Atlantic is still poorly understood due in part to low research effort in the tropics, and the degree of movement among regions is largely unknown (Mostello et al. 2014; Shealer \& Saliva, 1992; Spendelow et al. 2010). Geographical separation is unlikely to inhibit dispersal as roseate terns have high movement potential, and banded individuals have been observed in colonies far from their natal region during the breeding season (Shealer \& Saliva 1992; Hays et al. 1999). There are no physical barriers between the two populations, and Northwestern roseate terns use Caribbean islands as stopovers during their migration to South America (Nisbet 1984; Mostello et al. 2014), suggesting that seascape barriers 
are unlikely to compromise movement between regions. Additionally, the two populations are believed to overlap on their wintering grounds in South America (Nisbet 1984; Hays et al. 1999), which has been shown to promote interbreeding between distinct breeding populations in other seabirds (Friesen et al. 2007; Bicknell et al. 2012; Mariano-Jelicich \& Madrid 2014).

Here, we conduct the first investigation of genetic connectivity between both roseate tern populations in North America. To assess potential dispersal across the Atlantic, we also included samples from the Azores population, which is roughly equidistant from the Northwestern and Caribbean populations and can provide insight into large-scale cross-oceanic movement. Mitochondrial and microsatellite loci have been previously used to investigate roseate tern global connectivity, with populations found to be genetically differentiated between the Atlantic and Indo-Pacific oceanic basins and across the Atlantic (Lashko 2004), but with no genetic structuring found between colonies in the Northwest (Szczys et al. 2005; Dayton \& Szczys 2021). The Caribbean metapopulation was not included as part of this earlier study, and we do not have a good understanding of movement within the Caribbean (Nisbet \& Ratcliffe 2008). Additionally, roseate terns exhibit low genetic variability (Szczys et al. 2005; Dayton \& Szczys 2021), as is common in terns (Faria et al. 2007; Mariano-Jelicich \& Madrid 2014), which can make identifying genetic structuring challenging with low-quantity markers such as microsatellites. Due to this low genetic variation, we supplemented microsatellite markers with single nucleotide polymorphisms (SNPs) derived from capture and sequencing of Ultra-Conserved Elements (UCEs; Faircloth et al. 2012) .

UCEs have successfully been applied to resolve phylogenetic relationships among closely related species complexes for a variety of taxa (Everson et al. 2019; Oswald et al. 2019; Tsai et al. 2019; Winker et al. 2018), but application within species and for more shallow timescales has been minimal (Parker et al. 2020). Using two sets of marker types enables comparison of results and validation of the effectiveness of UCEs for population-level questions.

Minimal genetic structuring among populations of roseate terns would be consistent with other studies of large-scale seabird connectivity in the absence of biogeographical impediments to movement, and would indicate that gene flow indeed occurs between these two populations. Alternatively, presence of genetic structuring between these populations may indicate disruption of historical dispersal patterns resulting from extensive population declines in the 20th century, a theory that could be supported by findings of low genetic diversity and recent population bottlenecks in one or both metapopulations.

\section{Materials And Methods}

\section{Sample Collection and DNA Preparation}

We collected samples from roseate tern chicks over 2017-18 from Leduck Island in the U.S. Virgin Islands (USVl; $n=37$ ) and from 3 sites in the Florida Keys (FL; $n=26$; Fig. 1). Blood was collected by extracting $<25 \mu \mathrm{l}$ from the tarsal veins of chicks. Samples were stored in Queen's lysis buffer. We collected blood samples only from chicks, which were captured by hand at nest sites, and sampled only chicks $<3$ days old to facilitate rapid capture. Only one individual was sampled per nest. Because of high 
yearly site turnover and apparent mixing between colonies in the VI (Pierce 2009), genetic structuring is likely to be minimal, and the samples from Leduck Island were assumed to be representative of this population. We also opportunistically salvaged tissue from deceased chicks and eggs. Blood samples from Massachusetts (MA; $n=35$ ) were collected in 2017 by the Massachusetts Division of Fisheries and Wildlife using similar methods. As the Northwestern population has been demonstrated to be panmictic (Szczys et al. 2005; Dayton \& Szczys 2021), we assumed that the MA colonies would be representative of roseate tern genetic variation within the Northwestern Atlantic. Tissue samples were salvaged from chicks subsequent to depredation in the Azores $(A Z ; n=10)$ in 2018 by researchers from the University of Azores.

We extracted DNA from all sample types using Qiagen DNeasy blood and tissue kits (Qiagen, Hilden, Germany) following recommended protocols and with a modified 24-hour digestive period for tissue samples. We quantified sample concentration using a Qubit Fluorometer (Invitrogen, Carlsbad, CA) and removed samples with DNA concentrations below a minimum of $0.05 \mathrm{ng} / \mu \mathrm{l}$ from further analysis.

\section{Microsatellite Genotyping}

We amplified 14 microsatellite markers previously optimized for roseate terns in Dayton and Szczys (2021; see Table S1 for microsatellite sequences and conditions). Independent triplicates were run for low-quality $(\leq 2.0 \mathrm{ng} / \mu \mathrm{l})$ samples, samples obtained from tissue, and samples with evidence of null alleles (i.e., failure to amplify at a specific locus). PCR conditions followed Szczys et al. (2005) with an initial denaturation of $2 \mathrm{~min}$ at $94^{\circ} \mathrm{C}, 35$ cycles of $30 \mathrm{~s}$ at $72^{\circ} \mathrm{C}, 30 \mathrm{~s}$ annealing at $50-58^{\circ} \mathrm{C}, 30 \mathrm{~s}$ touchdown at $72^{\circ} \mathrm{C}$, and 2 min extension at $72^{\circ} \mathrm{C}$. PCR product was loaded on an ABI PRISM 3100 (Applied Biosystems Foster City, CA, USA) to separate amplicons by size and visualize alleles.

We manually detected and scored microsatellite alleles using GENEMAPPER 3.7 (Applied Biosystems). We then checked microsatellite loci for evidence of null alleles and genotyping error via 10,000 Monte Carlo runs and 95\% confidence intervals in MICRO-CHECKER (Van Oosterhout, Hutchinson, Wills, \& Shipley, 2004), which tests alleles for evidence of excess homozygosity. We tested alleles for linkage disequilibrium and deviation from Hardy-Weinberg Equilibrium (HWE) using 10,000 Monte Carlo replicates in the R package 'adegenet' 2.1.3 (Jombart 2011) and removed loci in disequilibrium. For this and all analyses involving multiple comparisons, we corrected a levels at the significance threshold $a=$ 0.05 using a sequential Bonferroni correction (Rice 1989). Null alleles can lead to overestimation of genetic differentiation among sampling locations. We used the program FreeNA (Chapuis \& Estoup 2007) to investigate the effect of potential null alleles on population differentiation in microsatellites. FreeNA estimates the null frequencies for each locus and population and applies a correction to account for the positive bias of null alleles on Weir's $F_{S T}$ (Chapuis \& Estoup 2007).

\section{SNP Genotyping}

We prepared samples for genomic library construction by shearing DNA using a Biorupter with a target fragment size of < 500bp. Fragment size was visualized via 1\% agarose gel. After shearing, we prepared 
genomic libraries using the Blunt-end Single-Tube (BEST) method (Carøe et al. 2018), with sheared DNA fragments ligated to barcoded adapters and P7 and P5 Illumina primers, amplified for sequencing with 9-12 cycles, and purified using AMPure XP beads (Beckman Coulter, Inc.). We then quantified DNA concentration in multiplexed libraries using a Qubit Fluorometer and assessed mean fragment size using an Agilent 2200 TapeStation (Agilent Technologies, Santa Clara, CA). For UCE enrichment, we combined multiplexed libraries into 750 (150ng/library) pools. We then enriched equimolar pools for 5,060 UCE loci using the myBaits UCE Tetrapods 5Kv1 kit (Arbor Biosciences, Ann Arbor, MI) following the recommended protocol and with 16 cycles of post-enrichment PCR. We quantified fragment size distribution of enriched pools with a Bioanalyzer High Sensitivity dsDNA kit (Agilent Technologies, Santa Clara, CA). Enriched pools were then combined at equimolar ratios and sequenced at GENEWIZ (South Plainfield, NJ, USA) as paired-end 150bp reads on an Illumina HiSeq system.

Sequenced genomic reads were demultiplexed using Bcl2fastq 1.8.4 (Illumina). Following demultiplexing, we processed reads using the Phyluce bioinformatics pipeline, a set of programs set up for UCE sequence analysis (Faircloth, 2016). First, we cleaned reads by removing adapter contamination and low-quality bases with Illumiprocessor (Faircloth 2013), which processes reads via the trimming tool Trimmomatic 0.32.1 (Bolger et al. 2014). For de novo contig assembly, we chose a single modern sample with an intermediary number of reads (FL1843), which we reasoned would maximize recovery of UCE contigs while minimizing the amount of duplicate contigs, and therefore processing time. To prepare our reference, we assembled the reference sample's Read 1 and 2 files de novo using the Trinity 2.0.6 assembler (Grabherr et al. 2013), mapped the output contigs to a FASTA file of the 5,060 UCE probes using Phyluce, discarding duplicate contigs and non-UCE loci in the process, and then converted the results to our final reference FASTA file. We then aligned our raw, clean reads from each sample to the reference using the 'mem' algorithm in BWA 0.7.12 (Li \& Durbin 2010; Li 2013) and filtered the output using BWA and PicardTools 1.113 (http://picard.sorceforge.net) within the Phyluce wrapper. We then merged all individual Binary Alignment/Map (BAM) files into a single BAM file with Picard and indexed the output merged BAM with Samtools 0.1.19 (Li 2009).

To call SNPs and indels, we used HaplotypeCaller in GATK 4.1.8.1 (McKenna et al. 2010). We then used VCFtools 0.1.12b (Danecek et al. 2011) to filter SNPs by first removing indels and all loci below a Phredscaled minimum sequence quality of 30 , a minor allele count of 3 , a minimum read depth of 5 , and a maximum read depth of 100 . We then filtered out individuals with $>50 \%$ missing data and restricted loci to a maximum of $10 \%$ missing data. We removed loci out of HWE while controlling for a potential Wahlund effect by grouping individuals by sampling location, testing for deviation from HWE using 1000 Monte Carlo replicates in the package 'pegas', and removing loci out of HWE in any of the putative populations from all analyses using a sequentially Bonferroni-corrected significance threshold of $a=$ 0.05. To create our final dataset, we thinned loci randomly to one SNP per UCE locus to control for effects of linkage disequilibrium.

\section{Population Genetics}


To measure genetic diversity, we estimated observed and expected heterozygosity (respectively, $\mathrm{H}_{\mathrm{o}}$ and $H_{e}$ ) and rarefied allelic richness $\left(A_{R}\right)$ for each of the four sampling locations in the R package diveRsity (Keenan et al. 2013). To evaluate differences in genetic diversity among populations, we used a randomized one-way ANOVA with locus as a blocking factor to test for significant differences in $\mathrm{H}_{0}, \mathrm{H}_{\mathrm{e}}$ and $A_{R}$ among sampling locations and used Tukey testing to conduct multiple comparisons among population pairs if the ANOVA revealed significant interpopulation differences in a genetic diversity metric. We examined potential population differentiation with Weir \& Cockerham's $F_{S T}$ (Weir \& Cockerham 1984 ) in diveRsity, using $10^{4}$ bootstrap permutations to calculate bias-corrected $95 \%$ confidence intervals and test pairwise $F_{S T}$ for significant differences among sampling locations.

Roseate tern yearly census sizes based on nest counts are not necessarily indicative of genetic changes in the population, given that individuals appear to skip breeding years; thus, effective population size $\left(\mathrm{N}_{\mathrm{e}}\right)$ may provide a better estimate of number of breeding individuals within each population. To quantify $\mathrm{N}_{\mathrm{e}^{\prime}}$ we used the bias-corrected Linkage Disequilibrium (LD) method in the program NeEstimator v. 2.01. Estimates of $\mathrm{N}_{e}$ can be less precise with lower sample sizes and numbers of loci (Leberg 2005; England et al. 2006), and we therefore excluded the FL and AZ populations from the analysis and quantified $\mathrm{N}_{\mathrm{e}}$ only with the SNP dataset. We estimated $\mathrm{N}_{\mathrm{e}}$ separately for the NW and VI populations and report results from lowest allele frequency $\leq 02$ following the recommendations of Waples and Do (2010) and with parametric $95 \%$ confidence intervals.

To test sampling locations for signals of recent $\left(<4 N_{e}\right)$ population bottlenecks we used BOTTLENECK 1.2.02 (Cornuet \& Luikart 1996) to quantify differences between observed and expected heterozygosity under simulated mutation models. In BOTTLENECK, significant heterozygosity excess is taken as evidence of recent genetic bottlenecks under the assumption that allelic richness is lost from a population before heterozygosity with a rapid population decline. We removed AZ from the SNP analysis due to insufficient sample size (Cornuet \& Luikart 1996). For both microsatellites and SNPs, we used the sign test to investigate significant differences between heterozygosity excess and expected heterozygosity excess under mutation-drift equilibrium. We examined microsatellites under both a stepwise mutation model (SMM) and an intermediate two-phase model (TPM) with 90\% stepwise mutation, and examined SNPs under an infinite allele mutation (IAM) model, with 1000 iterations for all models.

\section{Population Structure}

We inferred population structuring or number of genetic clusters among our sampling locations for both microsatellite and SNP data using two methods. The first, STRUCTURE v. 2.3.4. (Pritchard 2000), uses Bayesian clustering to assign individuals to the most likely number of genetic populations through multilocus genotypes by grouping genotypes to minimize deviations from HWE and linkage equilibrium. For both marker types, we ran STRUCTURE simulations for 1-5 possible clusters $(K)$ using the admixture model with correlated allele frequencies and with sampling location both included and omitted as prior 
information. We ran 10 iterations each of $K=1-5$ with $10^{4} \mathrm{MCM}$ repetitions after a burn-in of $10^{4}$ generations. We used the online program STRUCTURE HARVESTER (Earl \& von Holdt 2012) to infer the most likely value of $K$ via the Evanno et al. (2005) method, which defines the best supported value of $K$ as that with the highest $\Delta K$, the rate of change in log probability of the data between successive $K$ values. The Evanno method does not return results from $K=1$, and we therefore validated results from the Evanno method with the mean log likelihood from each iteration of $K(\operatorname{LnP}(K))$, which can also be an effective means of identifying best-supported $K$ (Pritchard 2000). We then aligned clusters, merged STRUCTURE runs by $K$ value, and visualized output using the R package Pophelper 2.3.0 (Francis 2019).

STRUCTURE models can be sensitive to deviations from HWE and linkage equilibrium, which we suspected might occur if populations were substructured or subject to inbreeding. We therefore complemented analysis of population structuring in STRUCTURE with a Discriminant Analysis of Principal Components (DAPC) for both marker types in adegenet. DAPC is a multivariate analysis method that uses principal components (PCs) to infer genetic clustering and assign of individuals to groups by minimizing within-group variation(Jombart et al. 2010). DAPC has been empirically demonstrated to be better at detecting fine-scale clustering than STRUCTURE and, because it does not require a specified population genetics model for input, does not require loci to be in HWE (Jombart et al. 2010). Prior to implementing DAPC, we used the $K$-means clustering via the 'find.clusters' function to identify the most likely number of genetic clusters in our dataset without a priori population information, retaining all PCs, and selecting the number of clusters based on the Bayesian Information Criterion (BIC) value. For DAPC analysis, retaining a suboptimal number of PCs can cause model under or overfitting (Jombart et al. 2010). For both marker types, we used cross-validation with 1000 permutations to identify the optimal number of PCs as those that balanced the highest mean successful assignment of samples with the lowest mean squared error rate, and used this used this as input for the discriminate function analysis. We visualized results both without and with a priori genetic clusters to describe the relationships among putative populations. We used number of a priori clusters $(K=4)$ to assign individuals to most likely population of origin and to identify individuals that deviated from their prior group assignment based on retained discriminate functions. We cross-validated results for both marker sets by masking $25 \%$ of individuals from each population (but using $50 \%$ of individuals from AZ for SNP loci, as we only had 4 samples) to use as a test dataset in a DAPC analysis. We then used the predict.dapc function with the rest of the data as a training dataset, and evaluated assignment of the training data via posterior membership probabilities. For SNPs, we further investigated population assignment testing using Monte Carlo cross-validation in the R package assignPOP (Chen et al. 2018) with resampling iterations of 50\%, $70 \%$, and $90 \%$ of individuals with $50 \%, 75 \%$, and $100 \%$ of SNP loci, and with 100 replicates run for each proportion of individuals.

We investigated contemporary gene flow between regions using BayesAss 3.0.4 (Wilson \& Rannala 2003) for both markers with modifications for SNP analysis (Mussmann et al. 2019). BayesAss estimates recent ( $<3$ generations) unidirectional migration rate among populations as $m_{i j}$, with $m$ as the proportion of population $i$ resulting from gene flow from population $j$. We ran the program for $3 \times 10^{6}$ iterations, with 
a burn-in of $1 \times 10^{6}$ iterations and a sampling frequency of 2,000. To evaluate convergence of MCMC values we performed the analysis 5 times using different starting seeds and compared the posterior mean parameter estimates for each run to check concordance. Delta values were adjusted with a goal of a $20-60 \%$ acceptance rate for each parameter (Wilson \& Rannala 2005).

\section{Results}

\section{Microsatellite Genotyping}

Fourteen samples were excluded based on low concentration or failure to amplify (Table 1). No loci showed signs of significant LD. One microsatellite marker (IVGUD103) was monomorphic for all samples and was removed from further analysis. No loci showed evidence of scoring errors or evidence for large allele dropout, but 3 loci (AAT-27, AAC-20, and RGB-27) exhibited homozygote excess. Although homozygote excess can indicate presence of null alleles, no loci showed consistent homozygote excess across all populations. We found no substantial differences for pairwise $F_{S T}$ calculated with and without the null correction in FreeNA, suggesting that null alleles were unlikely to have a substantial effect on our results. Additionally, no loci exhibited high frequency of null alleles across all sites, and none exceeded an estimated frequency of $>0.21$ null alleles per locus per site (Table S2); therefore, we did not remove any loci based on null allele frequencies. When the 4 sampling regions were treated as separate populations, the only locus with significant HWE deviation across > 1 sampling location was Calbo-2 for both the USVI and NW Atlantic. We removed this locus from the analysis.

\section{SNP Genotyping}

37 samples were excluded based on low concentration, failure during library preparation, or failure to sequence (Table 1). Assembly of the specimen used to create our reference (FL1843) resulted in 21,839 contigs with a mean length of 722 base pairs (bp), for a total of 4,520 UCE loci representing 3,265,327 bp . Following sample alignment and filtering, we were left with a final SNP dataset of 3,385 total SNPs with an average per-site sequencing depth of $53 \times(S D \pm 37.91)$ per individual. With thinning by locus to remove loci out of linkage equilibrium and removal of 44 loci out of HWE, this resulted in 2,043 SNPS analyzed.

\section{Population Genetics}

For microsatellites, we found no evidence for differences among sampling locations (Table 1) for either $\mathrm{H}_{\mathrm{o}}\left(F_{3}=0.174, p=0.60\right), \mathrm{H}_{\mathrm{e}}\left(F_{3}=0.24, p=0.91\right)$, or $\mathrm{A}_{\mathrm{R}}\left(F_{3}=0.18, p=0.95\right)$. For SNPs, genetic diversity statistics (Table 1) differed significantly between sampling locations for $\mathrm{H}_{\mathrm{o}}\left(F_{3}=168, p<0.001\right), \mathrm{H}_{\mathrm{e}}\left(F_{3}=\right.$ $37.48, p<0.001)$, and $A_{R}\left(F_{3}=31.62, p<0.001\right)$. All 3 genetic diversity statistics were significantly lower for $A Z$ than the other 3 sampling locations $(p<0.001)$. Both $H_{o}(p=0.003)$ and $H_{e}(p=0.04)$ were significantly higher for the USVI than for MA, but there were no differences between other populations. All pairwise values of $F_{S T}$ were significantly different from 0 among populations except for USVI and FL for 
both microsatellites and SNPs (Table 2), indicating significant barriers to dispersal between all 3 populations. Differences in $\mathrm{N}_{\mathrm{e}}$ between sampling regions largely corresponded to census population size, with a smaller effective population size for $\mathrm{NW}\left(\mathrm{N}_{\mathrm{e}}=903.9 ; 95 \% \mathrm{Cl}\right.$ : 935.1, 3730.3) versus $\mathrm{VI}\left(\mathrm{N}_{\mathrm{e}}=1171.9\right.$; $95 \%$ Cl: 1278.0, 5038.7).

Results from BOTTLENECK did not agree between the two marker types. For microsatellites, no significant heterozygosity excess was detected in any regions under either the SMM or TPM models, suggesting absence of a bottleneck for all populations. Conversely, for SNPs, all regions exhibited significant heterozygosity excess at a level of $p<0.001$ under the IAM model, indicating presence of genetic bottlenecking for all 4 populations sampled.

\section{Population Structure}

We found strong evidence for population structuring between the NW and CAR. STRUCTURE results for both markers returned $K=2$ as the most likely number of genetic clusters among our four sampling locations (Fig. S1, a-d), with $\Delta K$ values supported by lower values of $(\operatorname{LnP}(K))$ at $K=1$ for all 4 treatments. For microsatellites, MA clustered separately from the other 3 sampling locations when location was included as a prior, and clustering was consistent with AZ as differentiated from MA at all levels of $K$ (Fig. 2a). For SNPs, MA also clustered separately from FL and the USVI, but AZ showed high proportions of relatedness to MA at all values of $K$ except $K=4$ (Fig. 2b). When location was not included as a prior, results did not differ for SNPs (Fig. S2a), but microsatellites showed greater admixture among all 4 sampling locations at all values of $K$ (Fig. S2b), indicating that microsatellites require location included as a prior to increase statistical power.

Structure analysis with DAPC also indicated a high degree of genetic structuring between the NW and CAR. Identification of optimal number of clusters with $K$-means clustering returned $K=4$ for microsatellites, while for SNPS output from $K$-means clustering was consistent with STRUCTURE output, with 2 clusters identified as optimal. For DAPC by optimal clusters, 5 PCs were retained for microsatellites, representing $53 \%$ of conserved variance, and 15 PCs were retained for SNPs, representing $34 \%$ of conserved variance. For microsatellites, samples grouped optimally did not clearly cluster by sampling location (Fig. 3a), with mixed groupings of all 4 regions in each cluster. For SNPs, samples were largely differentiated by region (Fig. 3b), with samples clustering as MA versus FL and the USVI, and with AZ split equally between groups.

When plotted as $K=4$ with a priori population groups as input, microsatellites were differentiated slightly by region (Fig. 3c), whereas SNPs clearly clustered individuals by region (Fig. 3d). DAPC from

microsatellites was able to correctly assign samples to sampling region $67 \%$ of the time, with assignment accuracy varying by population (AZ: 0.70, FL: 0.13, MA: 0.91, USVI: 0.67; Fig. S3). By contrast, DAPC from SNPs correctly assigned samples to region $100 \%$ of the time. For microsatellites, cross-validation with a reduced dataset resulted in an assignment accuracy rate of $52 \%$, with no population experiencing $100 \%$ accurate assignment (Fig. S4). Cross-validation of DAPC assignment for SNPs accurately assigned 
samples to sampling region $84 \%$ of the time (Fig. S5). Assignment accuracy of the reduced dataset was lower for FL (0.85) and the USVI (0.87), but $100 \%$ of samples were accurately assigned to prior population for AZ and MA. Results from Monte Carlo assignment testing based on SNPs were comparable to DAPC assignment testing for FL (0.67, with 0.32 assigning to USVI), MASS (0.99), and USVI (0.97), but accuracy was low for AZ (0.55), with 0.30 of AZ samples assigning to USVI, 0.06 to FL, and 0.06 to MASS. Overall assignment accuracy increased with proportion of individuals included in the training dataset (Fig. S5).

Consistent with population structuring results, we did not find evidence for recent migration between the NW and CAR, although results were indicative of movement with CAR and potentially between CAR and AZ. Bayesian estimates of gene flow were run with final delta values of 0.40 for migration rate and 0.90 for both allele frequency and inbreeding coefficient for microsatellites and migration rate of 0.27 , allele frequency 0.39 , and inbreeding coefficient 0.13 for SNPs. BayesAss inferred unidirectional rates of gene flow greater than 0 from the USVI into FL and AZ (Table 3). All other estimates of gene flow had confidence intervals that overlapped 0 (Table 3 ), suggesting that gene flow was negligible between other sampling locations.

\section{Discussion}

We found evidence for substantial genetic structure among roseate tern populations in the Atlantic Basin, with differentiation between metapopulations detected via significant $F_{S T}$, low levels of admixture between metapopulations as determined through both STRUCTURE and DAPC, and minimal evidence for migration between regions. Contrary to our prediction, this included significant differentiation between the Northwestern Atlantic and Caribbean populations, with results from both microsatellite and SNP markers indicating a lack of dispersal among roseate terns breeding in MA and the Caribbean. We found evidence of population bottlenecks in all sampling locations with SNP, but not microsatellite, markers. These results are consistent with the finding of no evidence for bottlenecking in samples from Massachusetts analyzed with 16 microsatellite loci (Dayton \& Szczys 2021). Evidence for bottlenecks via the SNP data suggests that differentiation between the two North American populations may be the recent result of genetic drift following population declines, although it is also possible that our results were due to ascertainment bias resulting from SNP filtering. Historically, the breeding range of roseate terns in the Northwestern Atlantic stretched down to the Carolinas (Soots \& Parnell 1974). Due to range contractions in the $20^{\text {th }}$ century, $90 \%$ of breeding roseate terns in the Northwestern Atlantic are now concentrated in only 3 primary colony sites in New England (USFWS 2020). It is possible that this range contraction, paired with extensive population declines, altered historical dispersal patterns of the Northwestern population and severed connectivity with the Caribbean.

Lack of interbreeding between the two populations may also be the result of assortative breeding due to adaptive differences between the two breeding populations, as has been noted in other seabird species with overlapping winter distributions but differing breeding habitat conditions (Lombal et al. 2017; Nunes 2018). Further work is needed to determine if behavioral and morphological differences between the two 
populations (Nisbet \& Ratcliffe 2008) have a genetic basis. Such differences would provide additional support for designation of the two North American metapopulations of breeding roseate terns as Evolutionary Significant Units (Moritz 1994). Given that both metapopulations may represent unique pools of genetic diversity, the loss of either would represent a considerable reduction in roseate tern genetic diversity on a global scale.

Within the Caribbean, we did not find evidence for significant differentiation between roseate terns in the USVI and FL via $F_{S T}$, and STRUCTURE plots for both markers were indicative of high admixture between the two regions. Estimates of contemporary gene flow between these two populations indicate that this is likely due to unidirectional dispersal from the USVI into FL. This finding of movement from the larger population to the smaller may be indicative of a source-sink relationship, with asymmetrical movement of dispersing individuals from a higher productivity site towards a site that does not provide reciprocal migrants (Pulliam, 1988). Roseate terns in FL have declined considerably in the $20^{\text {th }}$ and $21^{\text {st }}$ centuries and are nearing extirpation from the state (Gore et al. 2007; USFWS 2010). Reproductive success in FL appears to be lower than in other sites in Caribbean or the Northwest, as evidenced by lower hatch success and lower chick weight across growth stages (Zambrano 2007), with low reproductive success likely attributable to poor habitat quality (Zambrano et al. 2000). Based on our results, the maintenance of this population is due in part to influxes of breeders from other, more productive sites in the Caribbean, which has negative implications for the persistence of roseate terns in FL. However, these results may have been confounded by our inability to sample other breeding populations in the Caribbean. Roseate tern distribution in the greater Caribbean basin region is not well-known, but breeding colonies have been located in the Bahamas, and a large subpopulation is thought to be present in Cuba. It is probable that these subpopulations also share migrants with Florida and the Virgin Islands. Although existence of these unsampled "ghost populations" is unlikely to substantially influence estimates of migration (Beerli 2004), we can't fully discount the effects of potential dispersal across the greater Caribbean region on our findings.

Results were mixed for the relationship of roseate terns breeding in the Azores to those in the rest of the Atlantic. Both STRUCTURE and DAPC supported the presence of two genetic clusters in the Atlantic. However, although STRUCTURE from microsatellites and DAPC from SNPs clearly clustered the Caribbean and AZ populations apart from MA, STRUCTURE analysis of SNP data indicated a high degree of admixture between the MA and AZ populations. Although SNPs in general had higher resolution than microsatellite markers, sample size for the AZ was lower for the UCE analysis, with only 4 individuals sequenced versus 10 for microsatellites. Discordance between these results may in part be due to this smaller sample size, as inferences of genetic clustering can be unreliable with sample sizes smaller than $\mathrm{n}=5$ (Fogelqvist et al. 2010). We found similarly conflicting results between the two markers in analyses of migration rates, with microsatellites, but not SNPs, indicating significant rates of unidirectional movement from the USVI to AZ. Accuracy of Bayesian migration rate estimates increase with both sample size and number of markers (Wilson \& Rannala 2003). Although SNP-based analyses should provide higher statistical power to resolve movement and population structure (Fischer et al. 2017; Haasl 
\& Payseur 2011), the sample size for the SNP analysis was likely too low to effectively detect the presence of migrants within the AZ population. The fact that all other migration rates were largely concordant between SNP and microsatellite markers suggests that this is the case here, and that our microsatellite results may provide a more accurate depiction of levels of immigration from the USVI to the AZ. Despite this, the wide confidence intervals indicate that the actual proportion of Caribbean migrants within the AZ population is not well resolved due to the lower informativeness of microsatellite data.

Findings of migration from the USVI to the Azores provide the first evidence of potential roseate tern gene flow across the Atlantic Basin. A roseate tern banded on the wintering grounds in Brazil was found breeding in the Azores (Hays et al. 2002), and transatlantic movement has also been detected between Ireland and Massachusetts via banding resights (Nisbet \& Cabot 1995); however, it has not been verified if these movements are indicative of genetic exchange among populations. Past microsatellite analysis did not indicate evidence of gene flow between the AZ and the Northwestern population, but could not fully resolve relatedness due to low sample sizes and numbers of markers (Lashko 2004). Our results are consistent with prior findings of high genetic differentiation between the Northwestern and AZ populations (Lashko 2004), but suggest the potential for genetic exchange across the Atlantic via the Caribbean population. Roseate terns breeding in the Azores are subject to high rates of nest predation from invasive species, and reproductive success can be low and highly variable (Neves 2006). Unidirectional migration rates from the USVI to AZ may signal movement from a source population to a sink, with the Azores population unable to produce enough migrants to facilitate symmetrical dispersal, although it is again possible that our results are influenced by gene flow from unsampled populations in the Caribbean that may also send migrants to AZ. Additionally, we would expect lower differentiation between USVI and AZ if migrants regularly moved from the Caribbean to Europe, suggesting again that our understanding of dispersal between these regions is not fully resolved.

Diversity metrics recovered by both markers, as represented by allelic richness and observed heterozygosity, were low compared to other super-abundant seabird species (Wojczulanis-Jakubas et al. 2015, Yannic et al. 2016), but were largely consistent with studies of other breeding gulls and terns (Perez et al. 2020) and were comparable to past assessments of roseate tern genetic diversity (Lashko 2004; Dayton \& Szczys 2021). Results from SNP markers suggested that all 4 sampling locations showed evidence of recent declines, consistent with known population declines in both the early and mid-20 th century for the Northwestern population (USFWS 2020) and probable declines in the Florida and USVI populations. Assessments of genetic diversity within our four sampling sites were mixed, but results from SNP markers, which are considered more reliable for evaluating diversity metrics (Fischer et al. 2017), suggested significantly higher observed and expected heterozygosity in the USVI, the largest population sampled. This finding of lower genetic diversity in the smaller populations is suggestive of eroded genetic diversity resulting from population declines. Results from SNP markers suggested all 4 sampling locations showed evidence for recent declines, in line with known population declines in both the early 
and mid-20 $0^{\text {th }}$ century for the Northwestern population (USFWS 2020) and probable declines in the Florida and USVI populations.

Results based on microsatellite and SNP markers were largely in agreement, with both markers able to detect significant differentiation among populations and agreeing on the optimal number of population genetic clusters via Bayesian cluster analysis. This concordance suggests that SNPs derived from UCEanchored target sequences can to resolve population genomic questions at a shallower timescale than has been previously applied, as they were able differentiate populations within the same species and to quantify parameters such as migration rates for populations with minimal genetic structuring. Additionally, SNP markers derived from UCEs-anchored target sequences provided higher resolution data than microsatellites, based on their ability to more accurately assign samples to their breeding population, which provides support for the use of genomic data derived from next-generation sequencing in resolving population-level differentiation.

\section{Conservation Implications}

Population overlaps on wintering grounds are largely unknown for roseate terns on both sides of the Atlantic, with previous studies relying on band resights of individuals roosting on beaches at night (Hays et al. 1999). Our results suggest that movement between wintering grounds may contribute to crossoceanic dispersal in the Atlantic. A better understanding of roseate tern wintering ecology and migratory movements would contribute greatly to our understanding of dispersal among populations. The low success of tracking studies (Mostello et al. 2014) has previously made this challenging. Using population assignment to identify origin of individuals screened on migratory routes or wintering grounds has been investigated as a potential means of understanding overwintering dynamics in migratory birds, but fine scale assessment has largely been unsuccessful due to limited genetic structuring among populations (Connan et al. 2015; Gómez-Díaz et al. 2009) or use of uninformative genetic markers (Lovette et al. 2004). Higher-coverage genomic markers such as SNPs, which can better resolve fine-scale structure, can be used to more effectively identify unknown migratory birds to their natal regions (DeSaix et al. 2019). Given the high accuracy of population assignment with SNP markers, genetic analysis represents a promising tool for assigning individual roseate terns sampled on wintering grounds to population of origin, which can greatly expand our ability to understand population dynamics of nonbreeding roseate terns in the Atlantic Basin.

The lack of detectable dispersal between the Northwestern and Caribbean populations suggests that natural recolonization of either region is unlikely in the event of local extirpation. Similarly, dispersal from the Azores to the Western Atlantic appears to be rare, and past work has demonstrated high population differentiation between the UK and Azores population (Lashko, 2004), indicating that all 4 metapopulations of breeding roseate terns in the Atlantic are largely isolated despite apparent low levels of movement from the Caribbean to the Azores. This unexpected isolation has potential negative implications for their future persistence. If populations continue to decline, erosion of genetic diversity is unlikely to be offset by influxes of new alleles via migrants. Low diversity has the potential to 
compromise the adaptability of roseate terns in the face of changing climatic conditions, which is emerging as a primary threat to seabird persistence globally (Daunt \& Mitchell 2013; Oro 2014; Dias et al. 2019). Our study highlights the importance of continued conservation efforts for all breeding populations of roseate terns, with the ultimate goal of enhancing population sizes and encouraging recolonization of historically used breeding sites, thereby potentially enabling increased dispersal among breeding populations in the Atlantic Basin.

\section{Declarations}

\section{Acknowledgements}

Logistical support was provided by the USVI Division of Fish and Wildlife, the Florida Fish and Wildlife Conservation Commission, and the National Parks Service. We thank P. Szczys, C. Mostello, R. Zambrano, N. Warraich, C. Pavlik, D. Nellis, K. Kalasz, and V. Rodrigues Costa Neves for assisting with sampling and/or providing samples. We also thank Dr. Szczys and J. Dayton for their invaluable input for the microsatellite analysis and $\mathrm{S}$. Hauser for providing comments on the manuscript.

\section{Statements and Declarations}

\section{Funding}

This material is based upon work supported by the National Science Foundation Graduate Research Fellowship Program under Grant No. 1650114. Additional funding was provided by a Smithsonian shortterm visitor award, the United States Geological Society Ecosystems Mission Area, the David S. Lee Fund for the Conservation of Caribbean Birds, and United States Virgin Islands Division of Fish \& Wildlife Cays Restoration \& Research Grant VI-W-F17AF01314. Samples were collected and/or imported under appropriate United States Fish and Wildlife Service, United States Department of Agriculture, and regionspecific permits. All protocols were approved by the University of Louisiana at Lafayette Institutional Animal Care and Use Committee.

The authors have no relevant financial or non-financial interests to disclose

\section{Data Accessibility}

Raw sequence reads are deposited to the National Center for Biotechnology Information Nucleotide Database (PENDING). Related metadata, including individual sample identifiers with sampling region and corresponding SNP and microsatellite loci, as well as all code used to generate data, can be found at https://github.com/pabyerly/RoseateTern_PopulationGenetics.

\section{Author Contributions}

P.A.B conceived and designed the study, collected samples, conducted laboratory work and data analysis, interpreted the data, and wrote the paper. R.T.C and R.C.F participated in study design, interpreting the 
data, and drafting the manuscript. N.M. participated in laboratory work. N.A.S.P. particpated in study design and data analysis. P.L.L. participated in conceiving and designing the study, data analysis, interpretation of the data, and drafting the manuscript. All authors read and approved the final manuscript.

\section{References}

Athrey, G., D. L. Lindsay, R. F. Lance, and P. L. Leberg (2011). Crumbling diversity:

Comparison of historical archived and contemporary natural populations indicate reduced genetic diversity and increasing genetic differentiation in the Golden-cheeked Warbler. Conservation Genetics 12:1345-1355.

Beerli, P. (2004). Effect of unsampled populations on the estimation of population sizes and migration rates between sampled populations. Molecular Ecology 13:827-836.

Bensch, S., D. Hasselquist, N. Bo, and B. Hansson (1998). Higher fitness for philopatric than

for immigrant males in a semi-isolated population of great reed warblers. Evolution 52:877-883.

Bicknell, A. W. J., M. E. Knight, D. Bilton, J. B. Reid, T. Burke, and S. C. Votier (2012). Population genetic structure and long-distance dispersal among seabird populations: Implications for colony persistence. Molecular Ecology 21:2863-2876.

Buckley, P. A., and F. G. Buckley (1974). The endangered status of North American roseate terns. Colonial Waterbirds 4:166-173.

Carøe, C., S. Gopalakrishnan, L. Vinner, S. S. T. Mak, M. H. S. Sinding, J. A. Samaniego, N. Wales, T. Sicheritz-Pontén, and M. T. P. Gilbert (2018). Single-tube library preparation for degraded DNA. Methods in Ecology and Evolution 9:410-419.

Chapuis, M., and A. Estoup (2007). FreeNA manual. Molecular Biology and Evolution 24:621-631.

Chen, K. Y., E. A. Marschall, M. G. Sovic, A. C. Fries, H. L. Gibbs, and S. A. Ludsin (2018). assignPOP: An R package for population assignment using genetic, non-genetic, or integrated data in a machine-learning framework. Methods in Ecology and Evolution 9:439-446.

Chesser, R. K. (1991). Influence of gene flow and breeding tactics on gene diversity within populations. Genetics 129:573-583.

Connan, M., P. R. Teske, A. J. Tree, P. A. Whittington, and C. D. Mcquaid (2015). Subspecies assessment of Antarctic Terns (Sterna vittata) overwintering on the South African coast: evidence from morphology , genetics and stable isotopes. Emu 115:223-236. 
Cornuet, J.-M., and G. Luikart (1996). Description and power analysis of two tests for detecting recent population bottlenecks from allele frequency data. Genetics 144:2001-2014.

Cristofari, R., P. Plaza, C. E. Fernández, E. Trucchi, N. Gouin, C. Le Bohec, C. Zavalaga, J. Alfaro-Shigueto, and G. Luna-Jorquera (2019). Unexpected population fragmentation in an endangered seabird: the case of the Peruvian Diving-petrel. Scientific Reports 9:2021.

Crnokrak, P., and D. A. Roff (1999). Inbreeding depression in the wild. Heredity 83:260-270.

Daunt, F., and I. Mitchell (2013). Impacts of climate change on seabirds. MCCIP Science Review:125-133.

Dayton, J. and P. Szczys. (2021). Metapopulation connectivity retains genetic diversity following a historical bottleneck in a federally endangered seabird. Ornithological Applications 123: https://doi.org/10.1093/ornithapp/duab037

DeSaix, M. G., L. P. Bulluck, A. J. Eckert, C. B. Viverette, T. J. Boves, J. A. Reese, C. M. Tonra, and R. J. Dyer (2019). Population assignment reveals low migratory connectivity in a weakly structured songbird. Molecular Ecology 28: 2122-2135.

Dias, M. P., R. Martin, E. J. Pearmain, I. J. Burfield, C. Small, R. A. Phillips, O. Yates, B. Lascelles, P. G. Borboroglu, and J. P. Croxall (2019). Threats to seabirds: A global assessment. Biological Conservation 237:525-537.

Dirzo, R., H. S. Young, M. Galetti, G. Ceballos, N. J. B. Isaac, and B. Collen (2014). Defaunation in the Anthropocene. Science 345:401-406.

Earl, D. A., and B. M. vonHoldt. 2012. STRUCTURE HARVESTER: A website and program for visualizing STRUCTURE output and implementing the Evanno method. Conservation Genetics Resources 4:359-361.

Everson, K. M., J. F. McLaughlin, I. A. Cato, M. M. Evans, A. R. Gastaldi, K. K. Mills, K. G. Shink, S. M. Wilbur, and K. Winker (2019). Speciation, gene flow, and seasonal migration in Catharus thrushes (Aves: Turdidae). Molecular Phylogenetics and Evolution 139.

Faircloth, B. C. (2016). PHYLUCE is a software package for the analysis of conserved genomic loci. Bioinformatics 32:786-788.

Faircloth, B. C., J. E. McCormack, N. G. Crawford, M. G. Harvey, R. T. Brumfield, and T. C. Glenn (2012). Ultraconserved elements anchor thousands of genetic markers spanning multiple evolutionary timescales. Systematic Biology 61:717-726.

Faria, P. J., E. Baus, J. S. Morgante, and M. W. Bruford (2007). Challenges and prospects of population genetic studies in terns (Charadriiformes, Aves). Genetics and Molecular Biology 30:681-689. 
Fischer, M. C., C. Rellstab, M. Leuzinger, M. Roumet, F. Gugerli, K. K. Shimizu, R. Holderegger, and A. Widmer (2017). Estimating genomic diversity and population differentiation - an empirical comparison of microsatellite and SNP variation in Arabidopsis halleri. BMC Genomics 18:1-15.

Fogelqvist, J., A. Niittyvuopio, J. Ågren, O. Savolainen, and M. Lascoux (2010). Cryptic population genetic structure: The number of inferred clusters depends on sample size. Molecular Ecology Resources 10:314-323.

Frankham, R. (1996). Relationship of genetic variation to population size in wildlife. Conservation Biology 10:1500-1508.

Friesen, V. L., T. M. Burg, and K. D. McCoy (2007). Mechanisms of population differentiation in seabirds: Invited review. Molecular Ecology 16:1765-1785.

Funk, W. C., B. R. Forester, S. J. Converse, C. Darst, and S. Morey (2018). Improving conservation policy with genomics: a guide to integrating adaptive potential into U.S. Endangered Species Act: Decisions for conservation practitioners and geneticists. Conservation Genetics 20:115-134.

Francis, R. M. (2017). POPHELPER: an R package and web app to analyse and visualize population structure. Molecular Ecology Resources, 17:27-32.

Genovart, M., D. Oro, and F. Bonhomme (2003). Genetic and morphological differentiation between the two largest breeding colonies of Audouin's gull Larus audouinii. Ibis 145:448-456.

Given, A. D., A. Mills, and A. J. Baker (2002). Isolation of polymorphic microsatellite loci from the red-billed gull (Larus novaehollandiae scopulinus) and amplification in related species. Molecular Ecology Notes 2:416-418.

Gómez-Díaz, E., J. González-Solís, and M. A. Peinado (2009). Population structure in a highly pelagic seabird, the Cory's shearwater Calonectris diomedea: An examination of genetics, morphology and ecology. Marine Ecology Progress Series 382:197-209.

Haasl, R. J., and B. A. Payseur (2011). Multi-locus inference of population structure: a comparison between single nucleotide polymorphisms and microsatellites. Heredity 106:158-171.

Hailer, F., E.A. Schreiber, J. M. Miller, I. I. Levin, P. G. Parker, R. T. Chesser, and R. C. Fleischer (2011). Longterm isolation of a highly mobile seabird on the Galapagos. Proceedings. Biological sciences / The Royal Society 278:817-25.

Hays, H., P. C. Lima, L. Monteiro, J. DiCostanzo, G. D. Cormons, I. C. T. Nisbet, J. E. Saliva, J. A. Spendelow, J. Burger, J. Pierce, and M. Gochfeld (1999). A nonbreeding concentration of Roseate and Common Terns in Bahia, Brazil. Journal of Field Ornithology 70:455-464. 
Hays, H., V. C. Neves, and P. Lima (2002). Banded roseate terns from different continents trapped in the Azores. Journal of Field Ornithology 73:180-184.

Hess, G. R. (1996). Linking Extinction to Connectivity and Habitat Destruction in Metapopulation. The American Naturalist 148:226-236.

Hoban, S., M. Bruford, J. D'Urban Jackson, M. Lopes-Fernandes, M. Heuertz, P. A. Hohenlohe, I. Paz-Vinas, P. Sjögren-Gulve, G. Segelbacher, C. Vernesi, S. Aitken, L. D. Bertola, P. Bloomer, M. Breed, H. RodríguezCorrea, W. C. Funk, C. E. Grueber, M. E. Hunter, R. Jaffe, L. Liggins, J. Mergeay, F. Moharrek, D. O’Brien, R. Ogden, C. Palma-Silva, J. Pierson, U. Ramakrishnan, M. Simo-Droissart, N. Tani, L. Waits, and L. Laikre (2020). Genetic diversity targets and indicators in the CBD post-2020 Global Biodiversity Framework must be improved. Biological Conservation 248:108654.

Janowski, S., I. Gross, H. Sauer-Gürth, D. T. Tietze, M. Grohme, M. Frohme, P. Becker, and M. Wink (2016). New microsatellite markers for the Common Tern (Sterna hirundo) developed with 454 shot-gun pyrosequencing. The Open Ornithology Journal 9:50-59.

Johnson, J. A., M. R. Bellinger, J. E. Toepfer, and P. Dunn (2004). Temporal changes in allele frequencies and low effective population size in Greater Prairie-chickens. Molecular Ecology 13:2617-2630.

Jiang, H.X., S. L. Ren, Y. -Q. Hou, M. Yang, and X. -B. Wu (2011). Isolation and characterization of tetranucleotide repeat polymorphic microsatellite loci in Larus saundersi (Aves, Laridae). Genetics and Molecular Research 10:2034-2037.

Jombart, T., S. Devillard, and F. Balloux (2010). Discriminant analysis of principal components: A new method for the analysis of genetically structured populations. BMC Genetics:11:94.

Keenan, K., P. Mcginnity, T. F. Cross, W. W. Crozier, and P. A. Prodöhl (2013). DiveRsity: An R package for the estimation and exploration of population genetics parameters and their associated errors. Methods in Ecology and Evolution 4:782-788.

Lashko, A. (2004). Population genetic relationships in the roseate tern: globally, regionally and locally. $\mathrm{PhD}$ thesis, James Cook University, Australia.

Leigh, D. M., A. P. Hendry, E. Vázquez-Domínguez, and V. L. Friesen (2019). Estimated six per cent loss of genetic variation in wild populations since the industrial revolution. Evolutionary Applications 12:15051512.

Lombal, A. J., J. E. O'dwyer, V. Friesen, E. J. Woehler, and C. P. Burridge (2020). Identifying mechanisms of genetic differentiation among populations in vagile species: historical factors dominate genetic differentiation in seabirds. Biological Reviews 95:625-651.

Lombal, A. J., T. J. Wenner, J. L. Lavers, J. J. Austin, E. J. Woehler, I. Hutton, and C. P. Burridge (2017). Genetic divergence between colonies of Flesh-footed Shearwater Ardenna carneipes exhibiting different 
foraging strategies. Conservation Genetics 19:27-41.

Lovette, I. J., S. M. Clegg, and T. B. Smith (2004). Limited utility of mtDNA markers for determining connectivity among breeding and overwintering locations in three Neotropical migrant birds. Conservation Biology 18:156-166.

Mariano-Jelicich, R., and E. Madrid (2014). Microsatellite Variability Among Black Skimmer (Rynchops niger intercedens) populations in Southern South America. Waterbirds 37:175-182.

McCauley, D. J., M. L. Pinsky, S. R. Palumbi, J. A. Estes, F. H. Joyce, and R. R. Warner (2015). Marine defaunation: Animal loss in the global ocean. Science 347.

Monticelli, D., J. A. Ramos, and G. D. Quartly (2007). Effects of annual changes in primary productivity and ocean indices on breeding performance of tropical roseate terns in the western Indian Ocean. Marine Ecology Progress Series 351:273-286.

Moritz, C. (1994). Defining 'Evolutionarily Significant Units ' for conservation. Tree 9:373-375.

Mostello, C. S., I. C. T. Nisbet, S. A. Oswald, and J. W. Fox (2014). Non-breeding season movements of six North American roseate terns Sterna dougallii tracked with geolocators. Seabird 27:1-21.

Mussmann, S. M., M. R. Douglas, T. K. Chafin, and M. E. Douglas (2019). BA3-SNPs: Contemporary migration reconfigured in BayesAss for next-generation sequence data. Methods in Ecology and Evolution 10:1808-1813.

Neves, V. (2006). Towards a conservation strategy of the roseate tern Sterna dougallii in the Azores Archipelago. PhD thesis, University of Glasgow, Scotland.

Nisbet, I. C. T., and N. Ratcliffe (2008). Comparative demographics of tropical and temperate roseate terns. Waterbirds 31:346-356.

Nunes, G. T., and L. Bugoni (2018). Local adaptation drives population isolation in a tropical seabird. Journal of Biogeography 45:332-341.

Nuss, A., C. J. Carlos, I. B. Moreno, and N. J. R. Fagundes (2016). Population genetic structure of the Magnificent Frigatebird Fregata magnificens (Aves, Suliformes) breeding colonies in the Western Atlantic ocean. PLoS ONE 11:1-15.

O'Grady, J. J., B. W. Brook, D. H. Reed, J. D. Ballou, D. W. Tonkyn, and R. Frankham (2006). Realistic levels of inbreeding depression strongly affect extinction risk in wild populations. Biological Conservation 133:42-51.

Oro, D. (2014). Seabirds and climate: knowledge, pitfalls, and opportunities. Frontiers in Ecology and Evolution 2:1-12. 
Oswald, J. A., M. G. Harvey, R. C. Remsen, D. P. U. Foxworth, D. L. Dittmann, S. W. Cardiff, and R. T. Brumfield (2019). Evolutionary dynamics of hybridization and introgression following the recent colonization of Glossy Ibis (Aves: Plegadis falcinellus) into the New World. Molecular Ecology 28:16751691.

Parker, L., M. Hawkins, M. Camacho-Sanchez, M. Campana, J.A. West-Roberts, T. Wilbert, H. C. Lim, L. Rockwood, and J. Leonard (2020). Little genetic structure in a Bornean endemic small mammal across a steep ecological gradient. Molecular Ecology 29:4074-4090.

Pauls, S. U., C. Nowak, M. Bálint, and M. Pfenninger (2013). The impact of global climate change on genetic diversity within populations and species. Molecular Ecology 22:925-946.

Pierce, J. (2009). United States Virgin Islands. Pp. 99-111 in An Inventory of Breeding Seabirds in the Caribbean (P.E. Bradley and R.L. Norton, eds. University Press of Florida, Gainsville, FL.

Peery, M. Z., L. A. Hall, A. Sellas, S. R. Beissinger, C. Moritz, M. Bérubé, M. G. Raphael, S. K. Nelson, R. T. Golightly, L. Mcfarlane-Tranquilla, S. Newman, and P. J. Palsbøll (2010). Genetic analyses of historic and modern marbled murrelets suggest decoupling of migration and gene flow after habitat fragmentation. Proc. R. Soc. B 277:697-706.

Perez, G. S., K. S. Goodenough, M. H. Horn, R. T. Patton, E. A. Ruiz, E. Velarde, and A. Aguilar (2020). High connectivity among breeding populations of the Elegant Tern (Thalasseus elegans) in Mexico and Southern California revealed through population genomic analysis. Waterbirds 43:17-27.

Peterson, D. A., R. Hilborn, and L. Hauser (2014). Local adaptation limits lifetime reproductive success of dispersers in a wild salmon metapopulation. Nature Communications 5.

Pierson, J. C., D. J. Coates, J. G. B. Oostermeijer, S. R. Beissinger, J. G. Bragg, P. Sunnucks, N. H. Schumaker, and A. G. Young (2016). Genetic factors in threatened species recovery plans on three continents. Frontiers in Ecology and the Environment 14:433-440.

Pritchard, J. K. (2000). Inference of population structure using multi-locus genotypes. Genetics 155: 945959.

Pulliam, H. R. (1988). Sources, sinks, and population regulation. The American Naturalist 132:652-661.

Quillfeldt, P., Y. Moodley, H. Weimerskirch, Y. Cherel, K. Delord, R. A. Phillips, J. Navarro, L. Calderón, and J. F. Masello (2017). Does genetic structure reflect differences in non-breeding movements? A case study in small, highly mobile seabirds. BMC Evolutionary Biology 17:160.

Ralls, K., J. D. Ballou, M. R. Dudash, M. D. B. Eldridge, C. B. Fenster, R. C. Lacy, P. Sunnucks, and R. Frankham (2018). Call for a Paradigm Shift in the Genetic Management of Fragmented Populations. Conservation Letters 11:1-6. 
Reed, D. H., and R. Frankham (2003). Correlation between fitness and genetic diversity. Conservation Biology 17:230-237.

Schlesselmann, A.K. V., and B.C. Robertson (2017). Isolation and Characterization of 18 Polymorphic Microsatellite Loci for the Endangered New Zealand Black-Fronted Tern (Chlidonias albostriatus). Waterbirds 40:297-301.

Shealer, D. A., and J. E. Saliva (1992). Northeastern roseate terns seen at Puerto Rican colony during breeding season. Colonial Waterbirds 15:152-154.

Soanes, L. M., J. Pierce, D. Nellis, S. Zaluski, and L. G. Halsey (2020). Abundance and distribution of roseate terns (Sterna dougallii) in the Virgin Islands. Journal of Caribbean Ornithology 33:43-48.

Sonsthagen, S. A., R. E. Wilson, P. Lavretsky, and S. L. Talbot (2019). Coast to coast: High genomic connectivity in North American Scoters. Ecology and Evolution 9:246-7261.

Soots, R. F., and J. F. Parnell (1974). First Record of the roseate tern Nesting in North Carolina. The Chat:20-21.

Spendelow, J. A., C. S. Mostello, I. C. T. Nisbet, C. S. Hall, and L. Welch (2010). Interregional breeding dispersal of adult roseate terns. Waterbirds 33:242-245.

Sruoga, A., and D. Butkauskas (2006). Evaluation of the genetic structure of the breeding Common Tern (Sterna hirundo) population by means of microsatellite markers. Biologija 1:47-52.

Szczys, P., C. R. Hughes, and R. V. Kesseli (2005). Novel microsatellite markers used to determine the population genetic structure of the endangered roseate tern, Sterna dougallii, in Northwest Atlantic and Western Australia. Conservation Genetics 6:461-466.

Szczys, P., S. A. Oswald, and J. M. Arnold (2017). Conservation implications of long-distance migration routes: Regional metapopulation structure, asymmetrical dispersal, and population declines. Biological Conservation 209:263-272.

Tigano, A., M. Damus, T. P. Birt, J. A. Morris-Pocock, Y. B. Artukhin, and V. L. Friesen (2015). The Arctic: Glacial refugium or area of secondary contact? Inference from the population genetic structure of the Thick-billed Murre (Uria lomvia), with implications for management. Journal of Heredity 106:238-246.

Tirard, C., F. Helfenstein, E. Danchin (2002). Polymorphic microsatellites in the Black-legged Kittiwake Rissa tridactyla. Molecular Ecology Notes 2:431-433.

Tracy, L. N., and I. G. Jamieson (2011). Historic DNA reveals contemporary population structure results from anthropogenic effects, not pre-fragmentation patterns. Conservation Genetics 12:517-526. 
Tsai, W. L. E., C. Mota-Vargas, O. Rojas-Soto, R. Bhowmik, E. Y. Liang, J. M. Maley, E. Zarza, and J. E. McCormack (2019). Museum genomics reveals the speciation history of Dendrortyx Wood-partridges in the Mesoamerican highlands. Molecular Phylogenetics and Evolution 136:29-34.

U.S. Fish and Wildlife Service (2010). Caribbean roseate tern and North Atlantic roseate tern (Sterna dougallii dougallii), 5-year review: summary and evaluation. U.S. Fish and Wildlife Service, Boquerón, PR, and Concord, $\mathrm{NH}$.

U.S. Fish and Wildlife Service (2020). roseate tern Northeastern North American Population (Sterna dougallii dougallii) ), 5-year review: summary and evaluation. U.S. Fish and Wildlife Service, Concord, NH.

Van Oosterhout, C., W. F. Hutchinson, D. P. M. Wills, and P. Shipley (2004). MICRO-CHECKER: Software for identifying and correcting genotyping errors in microsatellite data. Molecular Ecology Notes 4:535-538.

Waples, R. S., and C. Do (2010). Linkage disequilibrium estimates of contemporary Ne using highly variable genetic markers: A largely untapped resource for applied conservation and evolution. Evolutionary Applications 3:244-262.

Weir, B. S., and C. C. Cockerham (1984). Estimating F-Statistics for the Analysis of Population Structure. Evolution 38:1358.

Welch, A. J., R. C. Fleischer, H. F. James, A. E. Wiley, P. H. Ostrom, J. Adams, F. Duvall, N. Holmes, D. Hu, J. Penniman, and K. A. Swindle (2012). Population divergence and gene flow in an endangered and highly mobile seabird. Heredity 109:19-28.

Wilson, G. A., and B. Rannala (2003). Bayesian inference of recent migration rates using multilocus genotypes. Genetics 163:1177-91.

Winker, K., T. C. Glenn, and B. C. Faircloth (2018). Ultraconserved elements (UCEs) illuminate the population genomics of a recent, high-latitude avian speciation event. PeerJ, 6, e5735- e5735.

Wojczulanis-Jakubas, K., A. Kilikowska, J. Fort, M. Gavrilo, D. Jakubas, and V. Friesen (2015). No evidence of divergence at neutral genetic markers between the two morphologically different subspecies of the most numerous Arctic seabird. Ibis 157:787-797.

Yannic, G., J. M. Yearsley, R. Sermier, C. Dufresnes, O. Gilg, A. Aebischer, M. V. Gavrilo, H. Strøm, M. L. Mallory, R. I. Guy Morrison, H. G. Gilchrist, and T. Broquet (2016). High connectivity in a long-lived highArctic seabird, the Ivory Gull Pagophila eburnea. Polar Biology 39:221-236.

Zambrano, R.( 2007). Reproductive success and nestling growth at a roof and ground colony of roseate terns (Sterna dougallii) in Florida. Masters Thesis, Florida Atlantic University, Boca Raton, Florida.

Zambrano, R., H. T. Smith, and M. Robson (2000). Summary of breeding roseate terns in the Florida Keys: 1974-1998. Florida Field Naturalist 28:64-68. 


\section{Tables}

Table 1. Comparison of summary genetic diversity statistics (and $95 \%$ confidence intervals) for roseate terns from 4 sampling locations based on microsatellite and single nucleotide polymorphic (SNP) markers.

\begin{tabular}{llllll} 
Marker type & site & $n$ & $A_{R}$ & $H_{o}$ & $H_{e}$ \\
\hline microsatellites & MA & 35 & 2.54 & $0.35(0.21,0.49)$ & $0.38(0.25,0.52)$ \\
\hline & FL & 16 & 2.76 & $0.29(0.19,0.40)$ & $0.38(0.23,0.53)$ \\
& USVI & 33 & 2.52 & $0.37(0.23,0.50)$ & $0.40(0.26,0.54)$ \\
\hline & AZ & 10 & 2.75 & $0.36(0.21,0.49)$ & $0.39(0.25,0.52)$ \\
\hline SNPs & & & & & \\
\hline & MA & 24 & 1.35 & $0.19(0.19,0.20)$ & $0.20(0.19,0.21)$ \\
\hline & FL & 13 & 1.38 & $0.21(0.20,0.21)$ & $0.21(0.20,022)$ \\
\hline & USVI & 30 & 1.38 & $0.21(0.21,0.22)$ & $0.22(0.21,0.23)$ \\
\hline & AZ & 4 & 1.26 & $0.10(0.09,0.10)$ & $0.16(0.15,0.17)$
\end{tabular}

MA = Bird Island, Massachusetts; FL = Florida Keys; USVI = Leduck Island, U.S. Virgin Islands; AZ = Praia Islet, Azores; $A_{R}=$ rarefied allelic richness; $H_{o}=$ observed heterozygosity; $H_{e}=$ expected heterozygosity

Table 2. $F_{S T}$ with $95 \%$ confidence intervals estimated from $10^{4}$ bootstraps based on microsatellite (below diagonal) and SNP (above diagonal) markers. Bolded values represent $F_{S T}$ values with estimated 95\% confidence intervals that do not overlap 0.

\begin{tabular}{lllll} 
& MA & USVI & $F L$ & $A Z$ \\
\hline MA & 0 & $\mathbf{0 . 0 5 ( 0 . 0 4 , 0 . 0 6 )}$ & $\mathbf{0 . 0 6}(\mathbf{0 . 0 4 , 0 . 0 7 )}$ & $\mathbf{0 . 1 2}(\mathbf{0 . 0 3 , 0 . 1 4 )}$ \\
\hline USVI & $\mathbf{0 . 0 9 ( 0 . 0 5 , 0 . 1 3 )}$ & 0 & $0.02(0.00,0.04)$ & $\mathbf{0 . 1 1}(\mathbf{0 . 0 4 , 0 . 1 3 )}$ \\
\hline FL & $\mathbf{0 . 1 2 ( 0 . 0 7 , 0 . 1 7 )}$ & $-0.00(-0.03,0.04)$ & 0 & $\mathbf{0 . 1 2}(0.04,0.16)$ \\
\hline AZ & $\mathbf{0 . 1 6 ( 0 . 1 0 , 0 . 2 3 )}$ & $\mathbf{0 . 0 9 ( 0 . 0 4 , 0 . 1 5 )}$ & $\mathbf{0 . 0 9 ( 0 . 0 3 , 0 . 1 7 )}$ & 0 \\
\hline
\end{tabular}

Table 3. Bayesian estimates of contemporary ( $\leq 3$ generations) gene flow among 4 roseate tern breeding locations with $95 \%$ confidence intervals. Bolded values represent migration rates with confidence intervals that do not overlap 0 . The arrow signifies direction of dispersal between pairs of populations. 


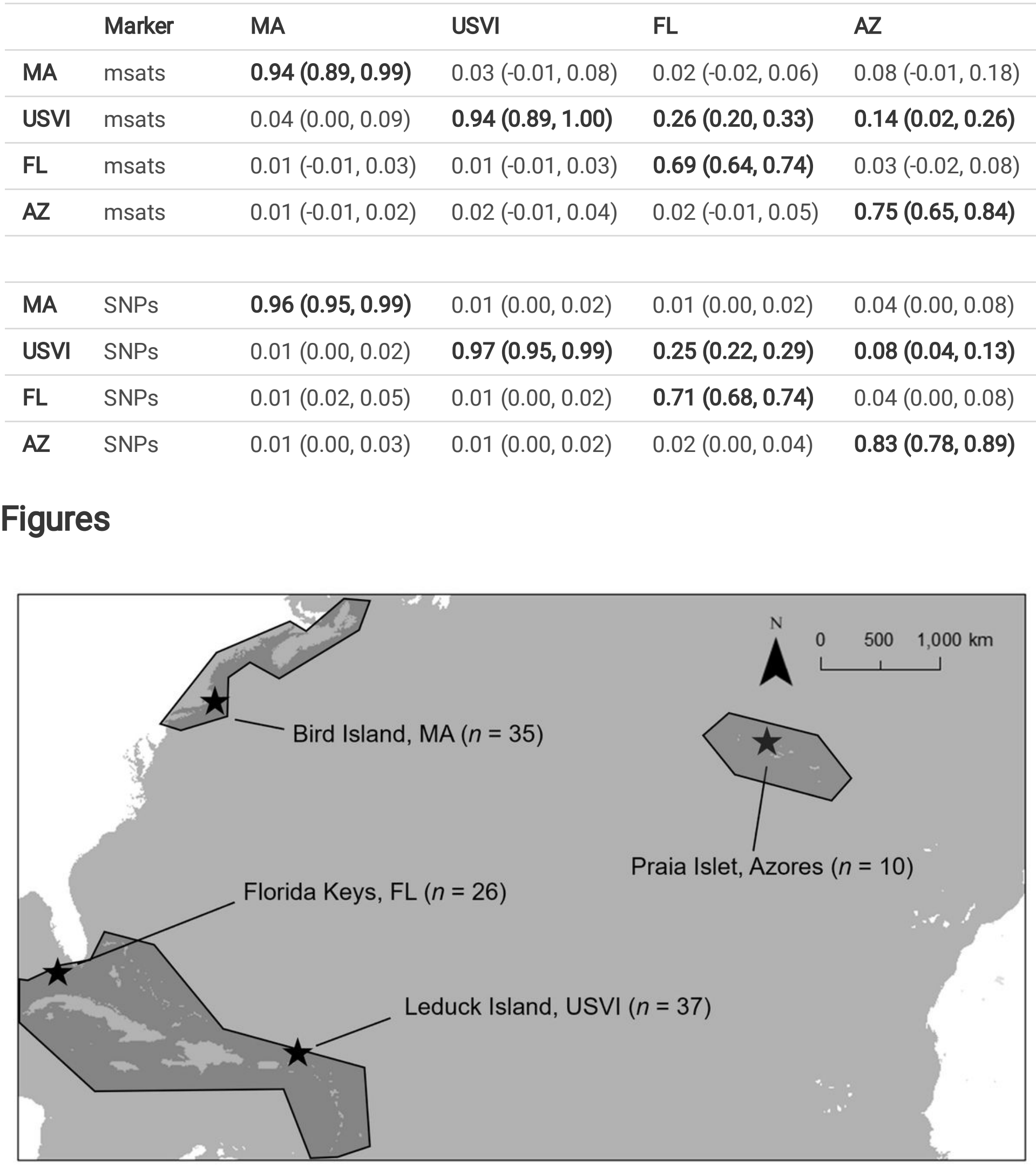

Figure 1 
Distribution of breeding roseate tern populations in the Atlantic Basin, with shading representing the approximate distribution of colonies in the Northeastern United States, the Caribbean, and the Azores. Sampling locations within populations are represented by stars.

(a)

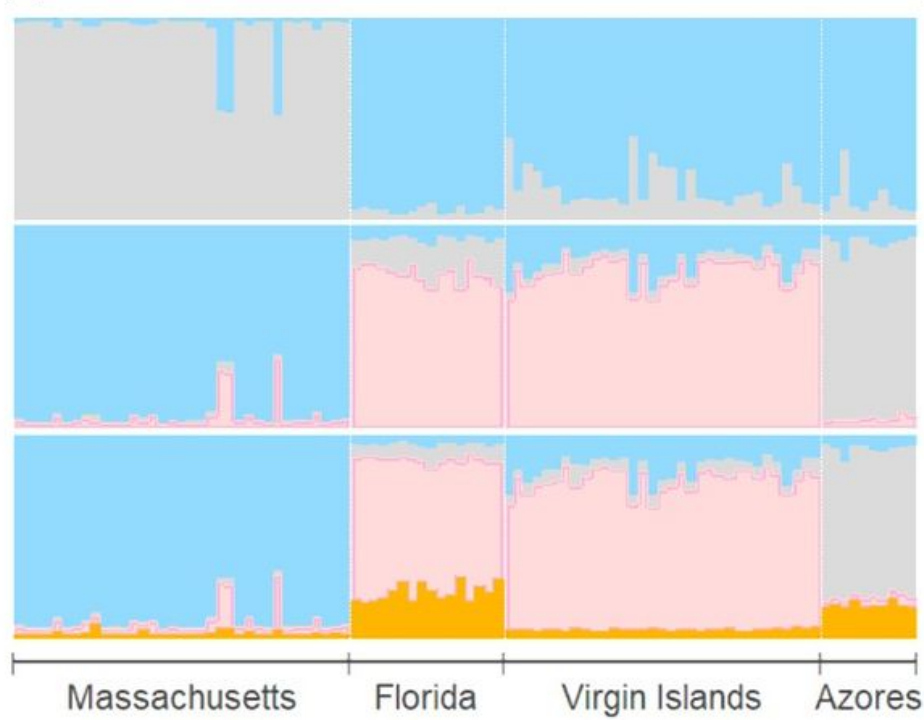

(b)

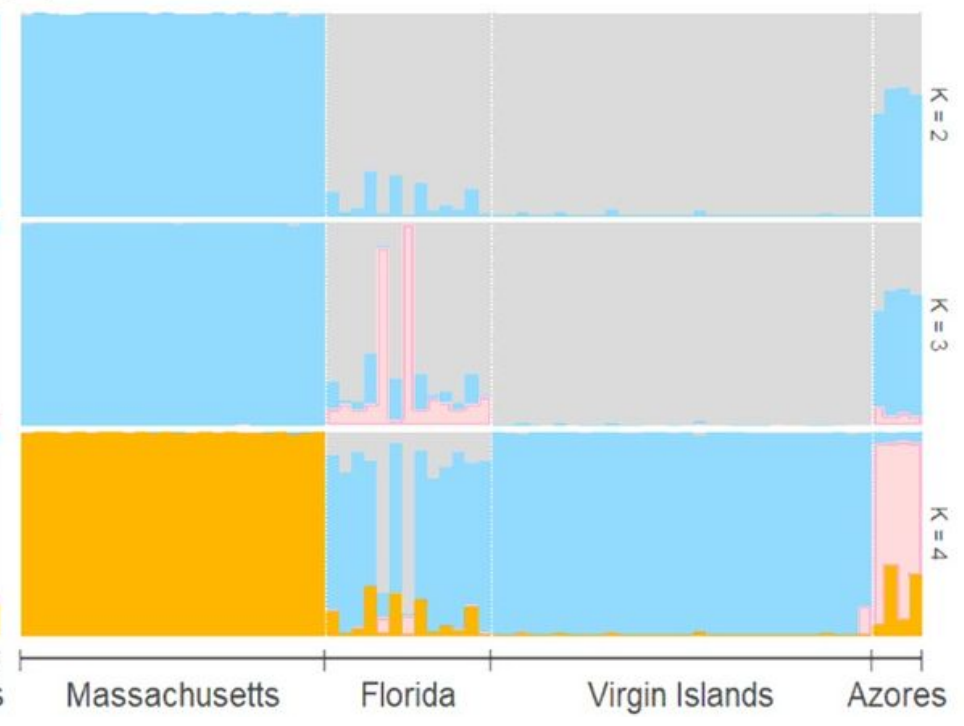

\section{Figure 2}

Genetic clustering inferred by Bayesian structure analysis in STRUCTURE for $K=2-4$ for a. microsatellite and $b$. SNP loci, with the $x$-axis representing sampling location and the $y$-axis representing proportion of group membership, and with sampling location as prior information. 
(a)

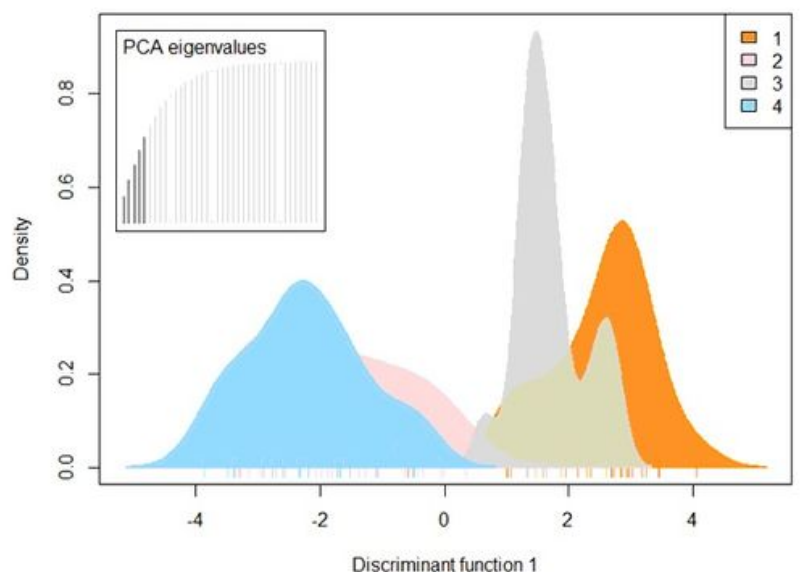

(c)

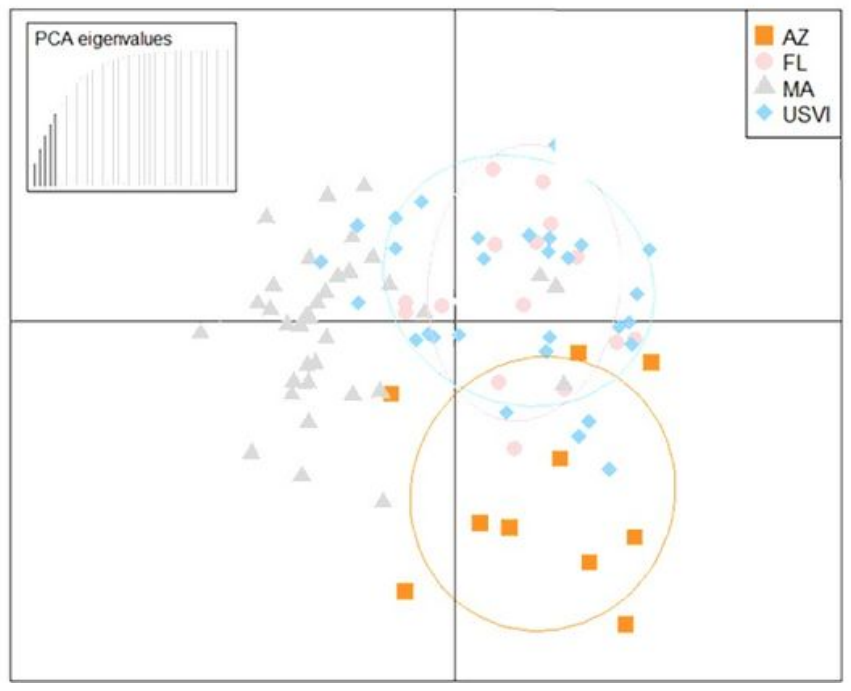

(b)

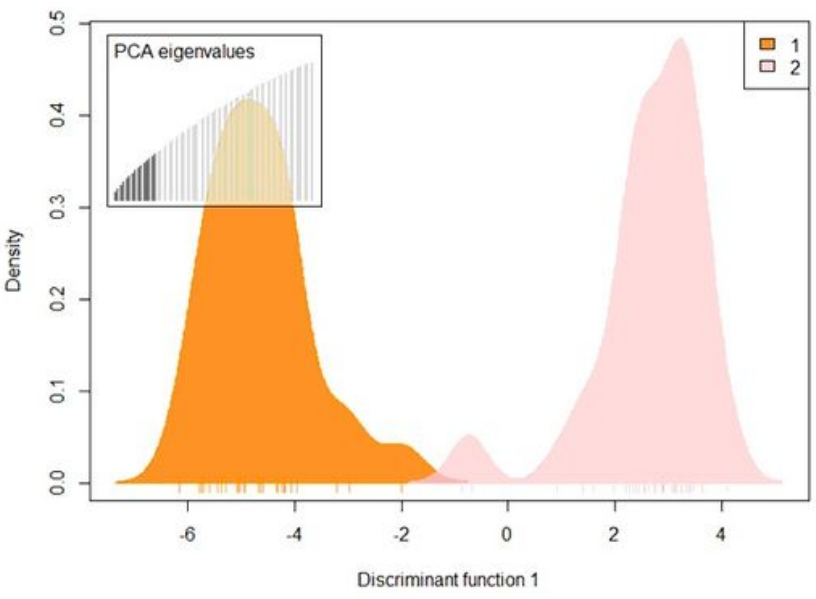

(d)

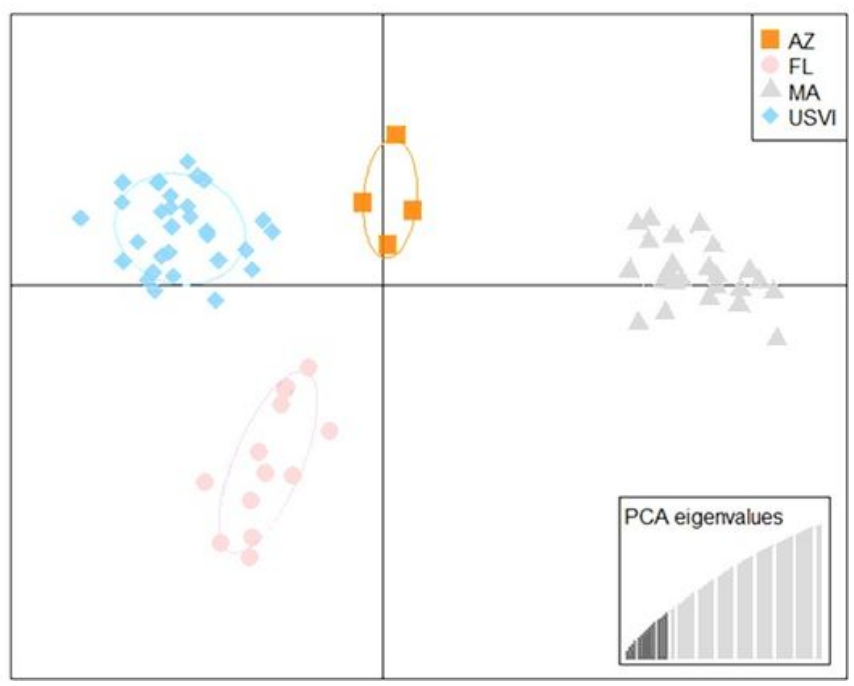

\section{Figure 3}

Discriminant analysis of principal components (DAPC) of roseate terns from 4 sampling locations in the Atlantic Basin. Results are plotted on 1 discriminate function with grouping by optimal number of clusters for a. microsatellite loci (with program-assigned groups 1, 2, 3, 4 consisting of mixed representatives from all 4 sampling regions) and $b$. SNP loci (with program-assigned group 1 consisting of individuals from $M A$ and group 2 of individuals from $A Z, F L$, and USVI). Results are plotted on 2 discriminate functions with a priori population grouping for $\mathrm{c}$. microsatellite and d. SNP loci, with shapes representing individuals, colors representing sample locations within ellipses designating grouping, and the $\mathrm{x}$ and $\mathrm{y}$ axes describing the first two discriminate functions. 


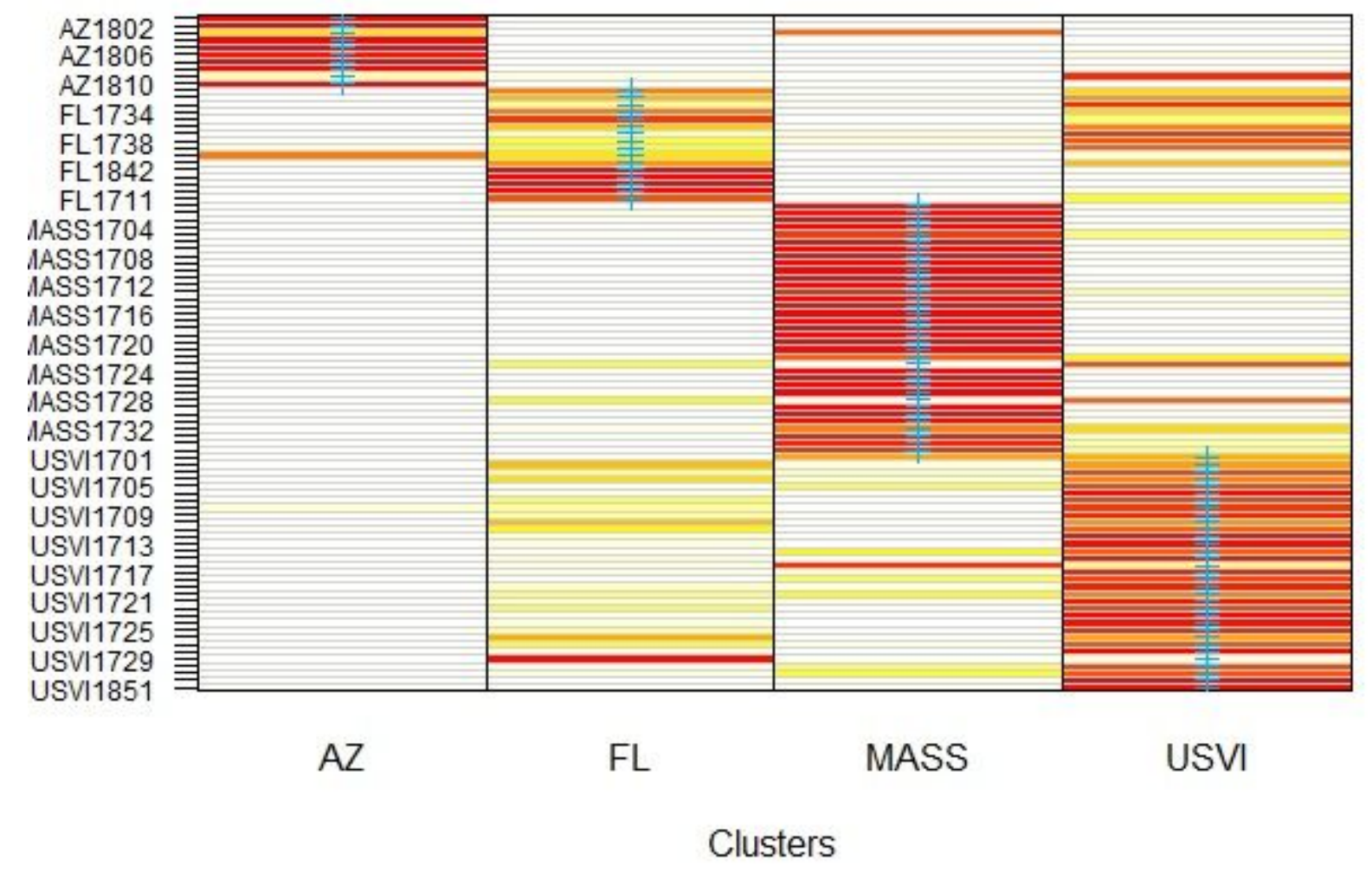

Figure 4

Population assignment based on microsatellite analysis of roseate terns from 4 sampling locations using clustering via Discriminant Analysis of Principal Components (DAPC). The $x$ axis represents sampling location and the $y$ axis individual samples. Blue crosses mark sampling locations. Colors represent population assignment, with assignment probability on a scale of red (high probability of assignment) to yellow (low probability of assignment).

\section{Supplementary Files}

This is a list of supplementary files associated with this preprint. Click to download.

- ByerlyEtAl11172021 supplemental.docx 